Argonne

\title{
Neutronics Analyses of the Minimum Original HEU TREAT Core
}

Nuclear Engineering Division 


\section{About Argonne National Laboratory}

Argonne is a U.S. Department of Energy laboratory managed by UChicago Argonne, LLC under contract DE-AC02-06CH11357. The Laboratory's main facility is outside Chicago, at 9700 South Cass Avenue, Argonne, Illinois 60439. For information about Argonne and its pioneering science and technology programs, see www.anl.gov.

\section{DOCUMENT AVAILABILITY}

Online Access: U.S. Department of Energy (DOE) reports produced after 1991 and a growing number of pre-1991 documents are available free via DOE's SciTech Connect (http://www.osti.gov/scitech/)

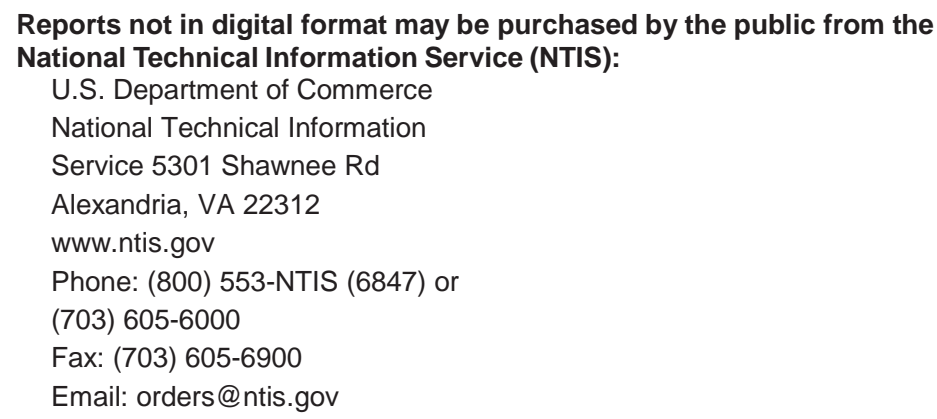

Reports not in digital format are available to DOE and DOE contractors from the Office of Scientific and Technical Information (OSTI):

U.S. Department of Energy

Office of Scientific and Technical Information

P.O. Box 62

Oak Ridge, TN 37831-0062

www.osti.gov

Phone: (865) 576-8401

Fax: (865) 576-5728

Email: reports@osti.gov

\section{Disclaimer}

This report was prepared as an account of work sponsored by an agency of the United States Government. Neither the United States Government nor any agency thereof, nor UChicago Argonne, LLC, nor any of their employees or officers, makes any warranty, express or implied, or assumes any legal liability or responsibility for the accuracy, completeness, or usefulness of any information, apparatus, product, or process disclosed, or represents that its use would not infringe privately owned rights. Reference herein to any specific commercial product, process, or service by trade name, trademark, manufacturer, or otherwise, does not necessarily constitute or imply its endorsement, recommendation, or favoring by the United States Government or any agency thereof. The views and opinions of document authors expressed herein do not necessarily state or reflect those of the United States Government or any agency thereof, Argonne National Laboratory, or UChicago Argonne, LLC. 


\section{Neutronics Analyses of the Minimum Original HEU TREAT Core}

prepared by

D. Kontogeorgakos, H. Connaway, G. Yesilyurt, and A. Wright

Nuclear Engineering Division, Argonne National Laboratory

sponsored by

U. S. Department of Energy, National Nuclear Security Administration Office of Material Management and Minimization

April 2014 


\section{Executive Summary}

This work was performed to support the feasibility study on the potential conversion of the Transient Reactor Test Facility (TREAT) at Idaho National Laboratory from the use of high-enriched uranium (HEU) fuel to the use of low-enriched uranium (LEU) fuel. The analyses were performed by the GTRI Reactor Conversion staff at the Argonne National Laboratory (ANL).

The objective of this study was to validate the MCNP model of the TREAT reactor with the welldocumented measurements which were taken during the start-up and early operation of TREAT. Furthermore, the effect of carbon graphitization was also addressed. The graphitization level was assumed to be $100 \%$ (ANL/GTRI/TM-13/4).

For this purpose, a set of experiments was chosen to validate the TREAT MCNP model, involving the approach to criticality procedure, in-core neutron flux measurements with foils, and isothermal temperature coefficient and temperature distribution measurements.

The results of this study extended the knowledge base for the TREAT MCNP calculations and established the credibility of the MCNP model to be used in the core conversion feasibility analysis. 


\section{Table of Contents}

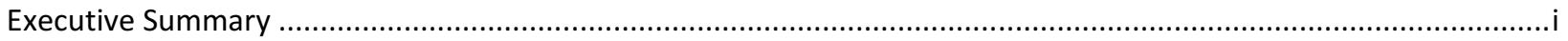

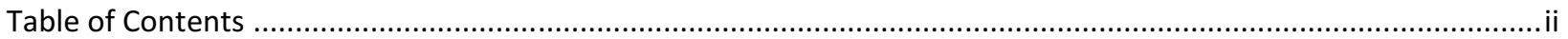

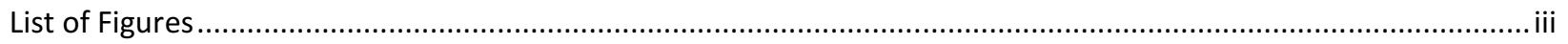

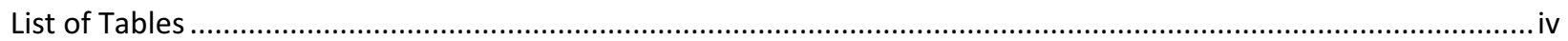

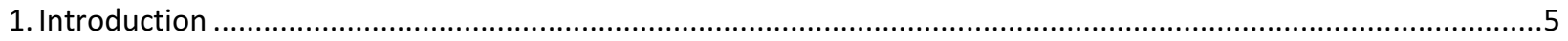

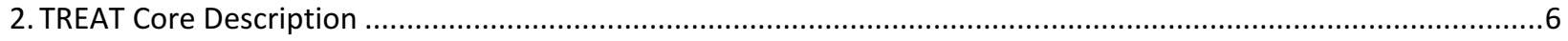

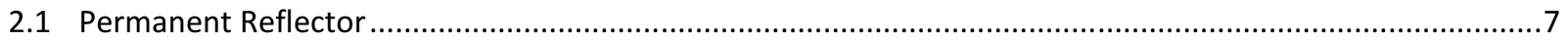

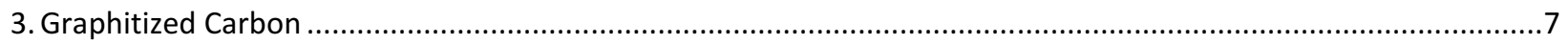

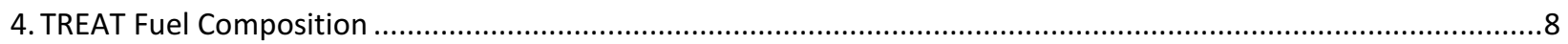

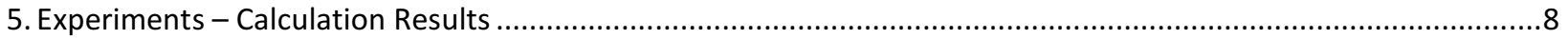

5.1 Minimum Core

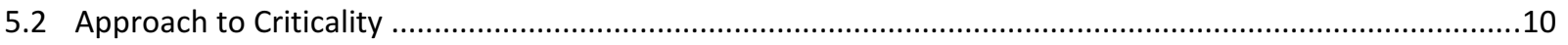

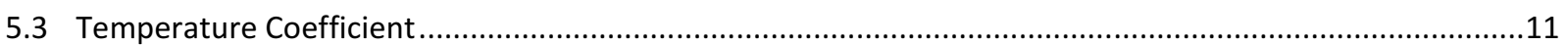

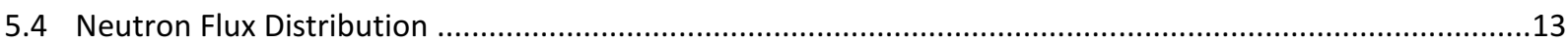

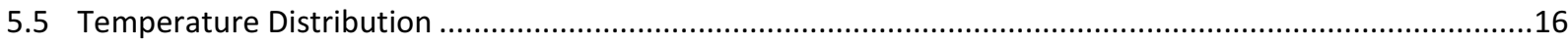

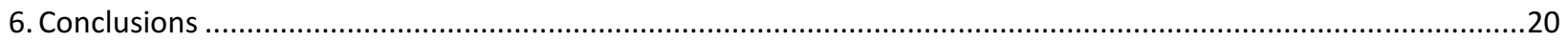

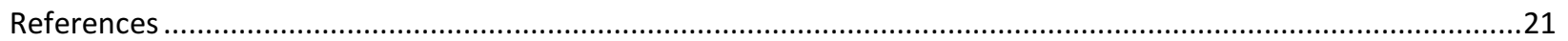

Appendix A: Changes in the MCNP Model (compared to ANL/GTRI/TM-13/4) ....................................................22

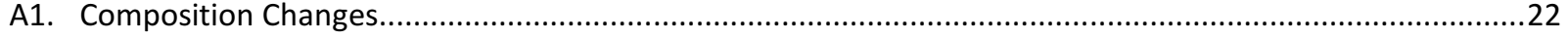

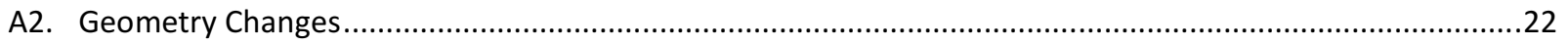




\section{List of Figures}

Figure [1.1]: Perspective View of TREAT.a. $\frac{\text { Page }}{5}$

Figure [1.2]: Plan View of TREAT (The Grid Plate Available Control Rod Positions are Shown)...............................6

Figure [5.1]: TREAT Minimum Critical Core Loading Map with 133 Standard (Red Solid Blocks) and 8 Control Fuel (Red Blocks with Hole at the Center) Assemblies. The 220 Green Blocks Represent the Graphite Aluminum Clad Reflector Assemblies and the 16 Green Blocks Labelled with ' Zr' the Zirc-3 Clad Reflector Assemblies. The Control

Rods were $100 \%$ Withdrawn.

Figure [5.2]: Loading Sequence of the Last 73 Fuel Elements Beginning with Loading \#1. The Final Loading is Consisted of 138 Standard (Red Blocks) and 8 Control Assemblies (Red Blocks with Hole in the Center). The 215 Green Blocks Represent the Aluminum Clad Graphite Reflector Blocks.

Figure [5.3]: MCNP Calculated Reactivity Loss as a Function of Uniform Core Temperature for $100 \%$ and 59\% Graphitization.

Figure [5.4]: TREAT Core Layout and the Position (Marked with White ' $x$ ') of the Foils Used to Measure the Neutron Flux Distribution.

Figure [5.5]: Measured and Calculated (100\% and 59\% Graphitization) Axial Relative to Maximum U-235 Fission Rate for the K-10 Core Position.

Figure [5.6]: Measured and MCNP Calculated (100\% and 59\% Graphitization) Radial (West) Relative to Maximum U-235 Fission Rate.

Figure [5.7]: Axial Distribution of the Relative to Maximum Au-197 Activation Rate for K-10 Core Position.

Figure [5.8]: TREAT Core Layout Used in Temperature Distribution Measurements. The Different Color of the Control Rods Located at the North-East Indicates that this Pair was Partially Inserted to Maintain Criticality. The Fuel Assemblies Marked Represent the Thermocouple Locations. Refer to Table 5.6 for the Exact Location of the Thermocouples.

Figure [5.9]: TREAT Fuel Heat Capacity as a Function of Temperature.

Figure [5.10]: Axial Relative-to-Maximum Temperature Distribution for Central Fuel Assembly (K-10). The Distance in the MCNP Results is from Core Center to the Center of the Fuel Assembly.................................................19

Figure [5.11]: Radial (East Direction) Relative-to-Maximum Temperature Distribution........................................19

Figure [5.12]: Radial (South Direction) Relative to Maximum Temperature Distribution.......................................20

Figure [A.1]: Upper Graphite Reflector and Outgas Tube of a Standard TREAT Fuel Assembly...............................23 Figure [A.2]: Cross-section View of Graphite Reflector Region, Including Outgas Tube, for a Control Rod TREAT Fuel Assembly. 


\section{List of Tables}

Table [2.1]: TREAT Design Characteristics.

Table [4.1]: Reference TREAT Fuel Composition Used in MCNP.

Table [5.1]: MCNP Criticality Calculations for the Minimum Core Configuration with 133 Standard and 8 Control

Fuel Assemblies for the Reported Combination of Aluminum and Zirc-3 Cladded Graphite Reflector Blocks.

Table [5.2]: MCNP Calculated Deviation from Criticality in pcm for the Minimum Core Configuration with 133

Standard and 8 Control Fuel Assemblies for the Reported Combination of Aluminum and Zirc-3 Cladded Graphite

Reflector Blocks.

Table [5.3]: MCNP Calculated $k_{\text {eff }}$ for the 73 Fuel Assemblies Loading for $100 \%$ and $59 \%$ Graphitization..................10

Table [5.4]: MCNP Calculated Reactivity Change as a Function of Uniform Temperature Distribution for TREAT (149std/8cntl)

Table [5.5]: Reported and MCNP Calculated Temperature Reactivity for Uniform Core Temperature and the Resulting Calculated to Measured Ratio (C/M).

Table [5.6]: Thermocouple Location Inside the Special Fuel Elements Used to Measure the In-Core Temperature..18 


\section{Introduction}

TREAT is a homogeneous, air-cooled, graphite-moderated and graphite-reflected reactor. The cut-away perspective view and top cross-sectional view of TREAT are shown in Figures 1.1 and 1.2, respectively. The reactor is fueled with $\mathrm{UO}_{2}$ particles which are finely dispersed in a graphite matrix. It was designed, built, and operated in a manner that allowed a wide range of fueled test samples to be placed in the core to be subject to a wide variety of power transients, all performed such that strict TREAT coretemperature limits would not be exceeded, even in the event of a reactivity accident. Flexibility was provided by a variety of core assemblies and by the nature of the uranium-bearing graphite fuel itself.

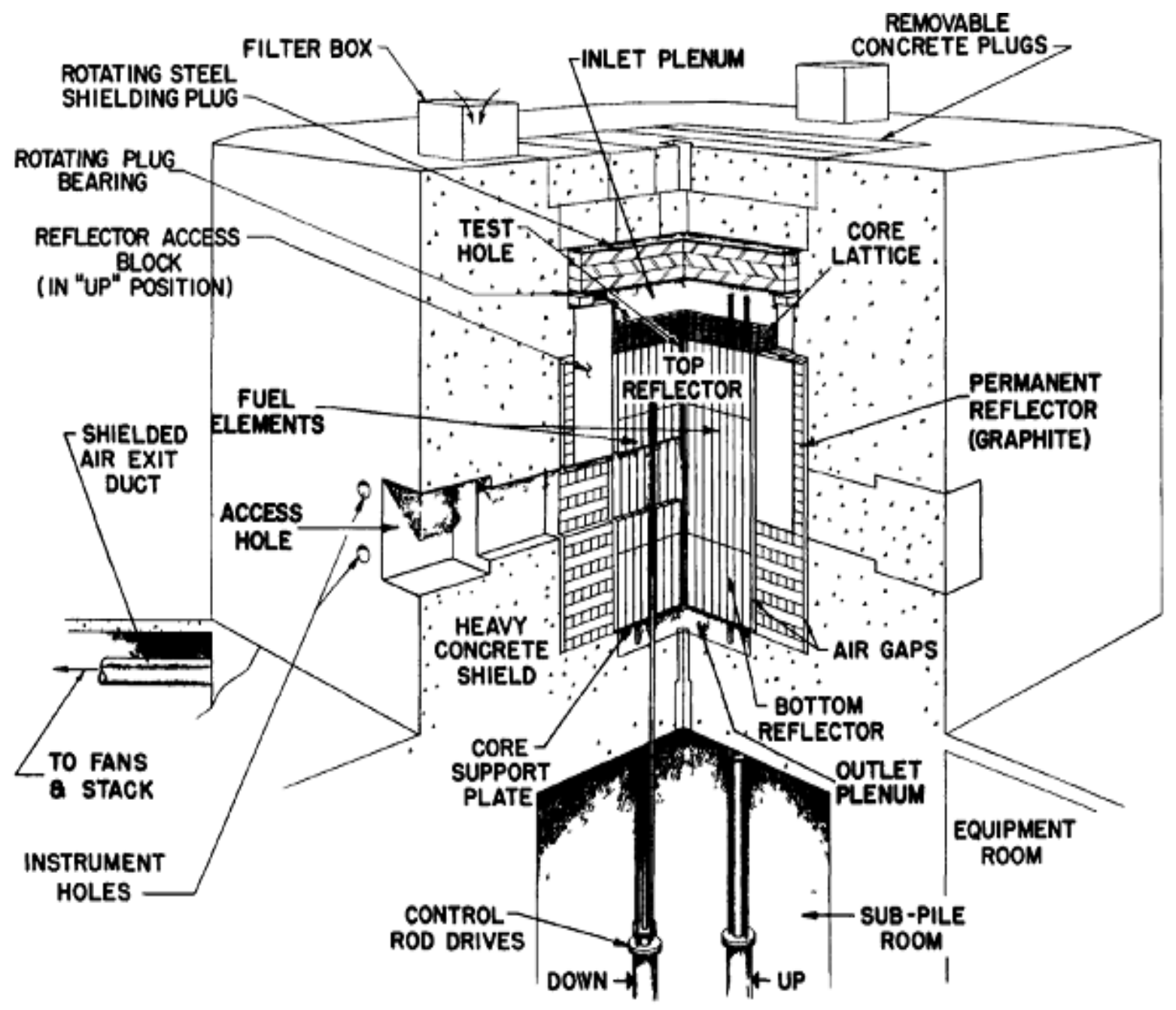

Figure [1.1]: Perspective View of TREAT 


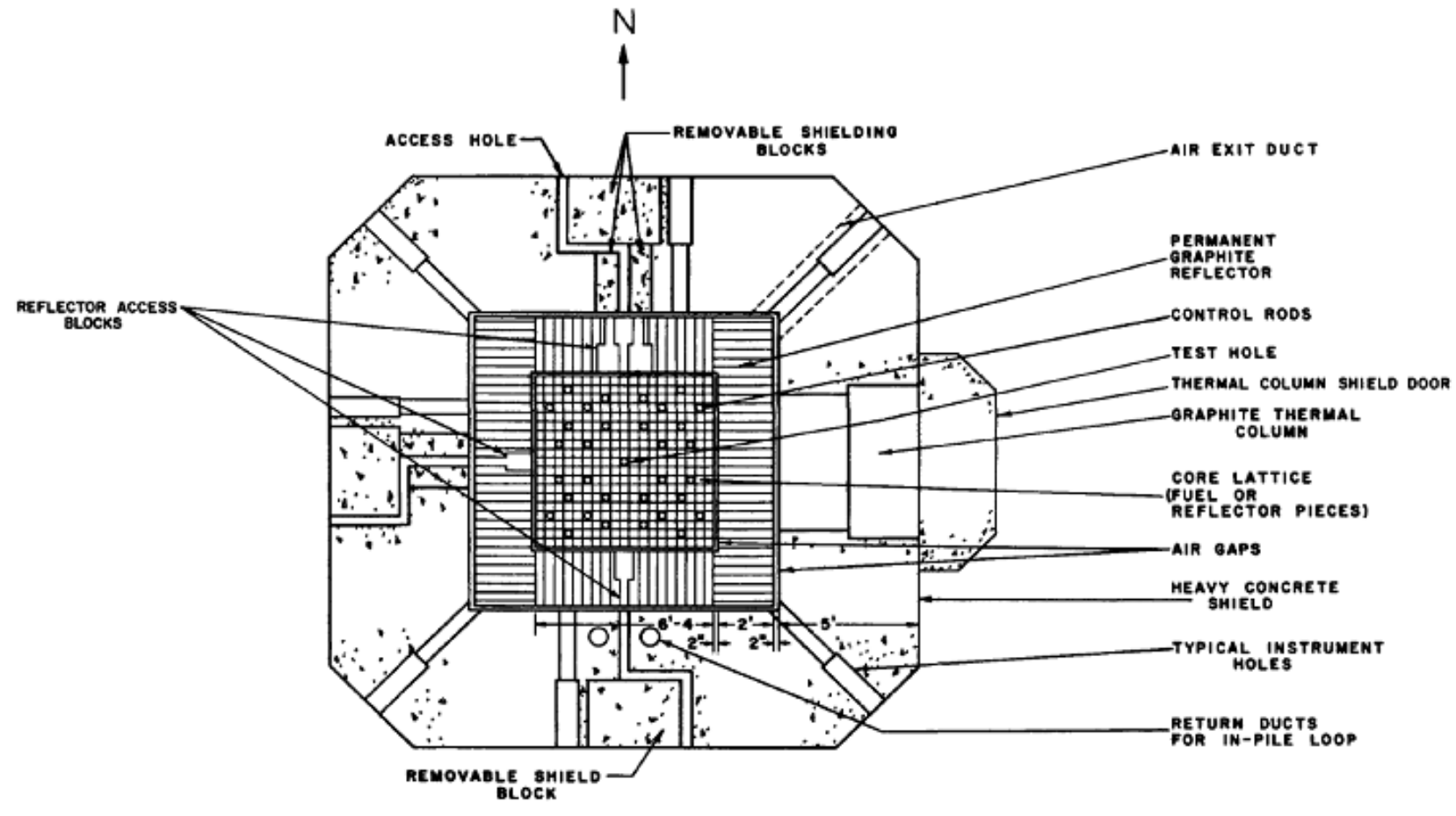

Figure [1.2]: Plan View of TREAT (the Grid Plate Available Control Rod Positions are Shown)

\section{TREAT Core Description}

A detailed description of TREAT can be found in the previous report ANL/GTRI/TM-13/4. A brief description of the core is presented in Table 2.1. Several changes have been applied to the TREAT MCNP model that was described in the previous report. The changes can be found in Appendix A. TREAT is a $\mathrm{UO}_{2}$-graphite fueled, graphite-moderated, graphite-reflected, air-cooled reactor. The reactor cavity is designed to accommodate a maximum core size of 76-inch $\times 76$-inch $\times 48$-inch $(1.9 \mathrm{~m} \times 1.9 \mathrm{~m} \times 1.22 \mathrm{~m})$ high, corresponding to a total of 361 fuel assemblies, each about 4-inch $\times 4$-inch $(10.16 \mathrm{~cm})$ square. Table 2.1 summarizes the design characteristics of TREAT.

Table [2.1]: TREAT Design Characteristics

\begin{tabular}{|c|c|}
\hline Core Parameter & Description \\
\hline Maximum Core Size (361 fuel assemblies) & 76 in. square, 48 in. high \\
\hline \multicolumn{2}{|l|}{ Fuel Assemblies } \\
\hline Overall Dimensions & 3.96 in. square $\times 8.94 \mathrm{ft}$. long \\
\hline Fuel section & $\begin{array}{l}\text { Six } 8 \text {-in.-long graphite-uranium blocks in } 25 \text {-mil } \\
\text { thickness of Zircaloy- } 3 \text { cladding, overall height } \\
47.625 \text { in. }\end{array}$ \\
\hline $\mathrm{UO}_{2}$ content & $0.248 w t \%$ \\
\hline Carbon to U-235 ratio & $10,000: 1$ \\
\hline U-235 enrichment & $93.1 \%$ \\
\hline Axial Graphite Reflector & 24 in. upper and lower, in 50 mils of Al cladding \\
\hline Radial Graphite Reflector & 24 in. thick \\
\hline Coolant & Air at atmospheric pressure \\
\hline
\end{tabular}


The basic TREAT fuel element assembly is about 4-inch $x$-inch and $8 \mathrm{ft}$ long. The upper and lower sections of the assembly contain 2 foot graphite regions with 50 mils $(0.050 \mathrm{in}$.) of aluminum cladding. The four-feet-long central section contains the fuel, an intimate mixture of enriched $\mathrm{UO}_{2}$ and graphite in the atomic ratio of 1 atom of U-235 to 10,000 atoms of carbon. This section is cladded by 25 mils thickness of Ziraloy-3 and was evacuated and sealed during manufacture.

In addition to the standard elements, the following special-purpose elements were used in the minimum core configurations:

a. Control elements: these have a 2-inch diameter lengthwise control rod hole;

b. Dummy elements: these are completely filled with graphite and used to fill out the matrix around the core and provide additional reflector thickness.

\subsection{Permanent Reflector}

The TREAT core is enclosed in a permanent radial reflector consisting of graphite blocks (4-inch $x$ 4-inch), stacked $7 \mathrm{ft}$ 8in. high and $2 \mathrm{ft}$ thick along the four inside walls of the shield cavity. There is a nominal 2inch gap on the inner and outer faces of the reflector for cooling flow. The reflector graphite was previously used in the CP-2 reactor.

The permanent reflector has large ( $275-\mathrm{lb})$ movable blocks of graphite installed in the regions facing the viewing slots of the core. The blocks move vertically and are supported in the "open" position by an aluminum lifting bracket mounted on the ledge of the concrete shield above the reflector. The south and west sides of the reflector each have one movable block which provides a slot of $4 \frac{1}{4}$-inch wide $\times 24$ inch high through the reflector. There are three movable blocks in the north side. The central block can be lifted to provide a slot 4 in. $\times 32$ in., or all three blocks can be removed (through the top rotating plug) to provide an opening of $141 \%$ in. $\times 32$ in. In the experiments modelled in this report, all of these gates were assumed to be closed (i.e., full of graphite).

There are two 6.5 in. diameter horizontal holes in each of the north, south, and west faces to accommodate installation of fast-response instruments close to the core. That radial reflector was secured in position with 46 stainless steel bolts of $1 \mathrm{in}$. diameter). The permanent reflector is supported by an angle iron spacers and a sheet metal framework anchored to the steel liner of the concrete shield cavity that surrounds the reflector. There is a gap formed by the spacers and support bars, which allows for the passage of coolant flow between the reflector and shield.

\section{Graphitized Carbon}

Previous analysis (ANL/GTRI/TM-13/4) assumed that all of the carbon contained in the TREAT fuel was fully graphitized. However, according to a paper submitted by RW Swanson et al [1] to the International Reactor Physics Conference (1988) in Jackson Hole, Wyoming, the fuel structure in TREAT is a complex mixture of crystalline graphite particles in a non-graphitized elemental carbon matrix. The best-estimate percentage graphitization is $59 \%$. In order to simulate with MCNP the different neutron scattering properties inside the TREAT fuel, the $S(\alpha, \beta)$ cross section treatment was applied to $59 \%$ of the total graphite atom density. The remaining $41 \%$ was simulated using the "free gas" approach. In Swanson's 
previous calculations (using hybridized cross sections), $\mathrm{k}_{\text {eff }}$ was increased by $2.2 \%$ when going from $100 \%$ to $59 \%$ graphitized carbon [1]. In order to further understand the effect of the carbon graphitization, the calculations documented in this report were performed applying the $S(\alpha, \beta)$ treatment to both $100 \%$ and $59 \%$ of the total carbon atom density in the TREAT fuel.

\section{TREAT Fuel Composition}

The composition of the TREAT fuel is not certain, and in 1970 Brittan and Doerner issued the intralaboratory memo "Reference Data for Calculations on TREAT-I" [2] to address the uncertainties and to propose the data to be used for future physics calculations. For the MCNP simulations reported in this study, this data set was used (with the slight adjustments detailed in the Appendices). The U-235 density in TREAT fuel was calculated by Brittan and Doerner using the inventory data from the records kept by the Argonne Special Materials group (shown in Table 4.1) [2].

Table [4.1]: Reference TREAT Fuel Composition Used in MCNP

\begin{tabular}{|cccc|}
\hline Fuel Element & Number & U-235 g /element & Element Volume $\left(\mathrm{cm}^{3}\right)$ \\
\hline Standard & 302 & 37.42115 & 11036.542 \\
\hline Thermocouple & 29 & 37.064137 & $\mathrm{n} / \mathrm{a}^{*}$ \\
\hline Slotted & 21 & 18.64194 & 5503.788 \\
\hline Control & 30 & 25.987 & 7708.884 \\
\hline
\end{tabular}

Since the volume of an element with thermocouple holes was not available, Brittan and Doerner calculated the average U-235 density as follows:

$$
\left(\frac{302 \times 37.42115}{11036.542}+\frac{21 \times 18.64194}{5503.788}+\frac{30 \times 25.987}{7708.884}\right) /(302+21+30)=3.3887 \times 10^{-3} \mathrm{~g} / \mathrm{cm}^{3} \text { of U-235 }
$$

\section{Experiments - Calculation Results}

The experiments discussed in the following sections were performed during TREAT's first six months of operation, using the minimum critical core. These tests were done to provide sufficient data on the operational characteristics of the reactor, and to yield information on the nuclear characteristics of the graphite-moderated system. The experiments are described in detail in the ANL-6173 report [4].

\subsection{Minimum Core}

The TREAT minimum critical core configuration represents the fuel loading necessary to achieve the criticality with all of the control rod fully withdrawn. This core was composed of 133 standard and 8 control fuel assemblies, with the rest of the grid plate positions occupied by elements described as graphite aluminum-cladded reflector blocks as shown in Figure 5.1. However, according to the intralaboratory memo by JR Liaw [5], not all of the graphite reflector blocks were aluminum cladded.

A number of Zirc-3 clad reflectors ( 25 mils clad thickness) were also used in the core positions, labeled as ' $Z r$ ' in Figure 5.1. The number of Zirc-3 clad reflectors ranged from 12 to 16 . The impact of the 
reflector block cladding on criticality was examined below. In this analysis, the gates on the north, west and south side of the radial reflectors were assumed to be closed and filled with graphite.

Table 5.1 shows the MCNP calculated $k_{\text {eff }}$ for $100 \%$ and $59 \%$ fuel graphitization where there were 133 standard and 8 control fuel assemblies with only aluminum-clad graphite reflector, and the results for cores with 12 and 16 Zirc-3 graphite reflector blocks. The standard deviation of the MCNP-computed results are shown in the columns headed "Std." For the same calculations, the deviation from criticality for every case is shown in Table 5.2.

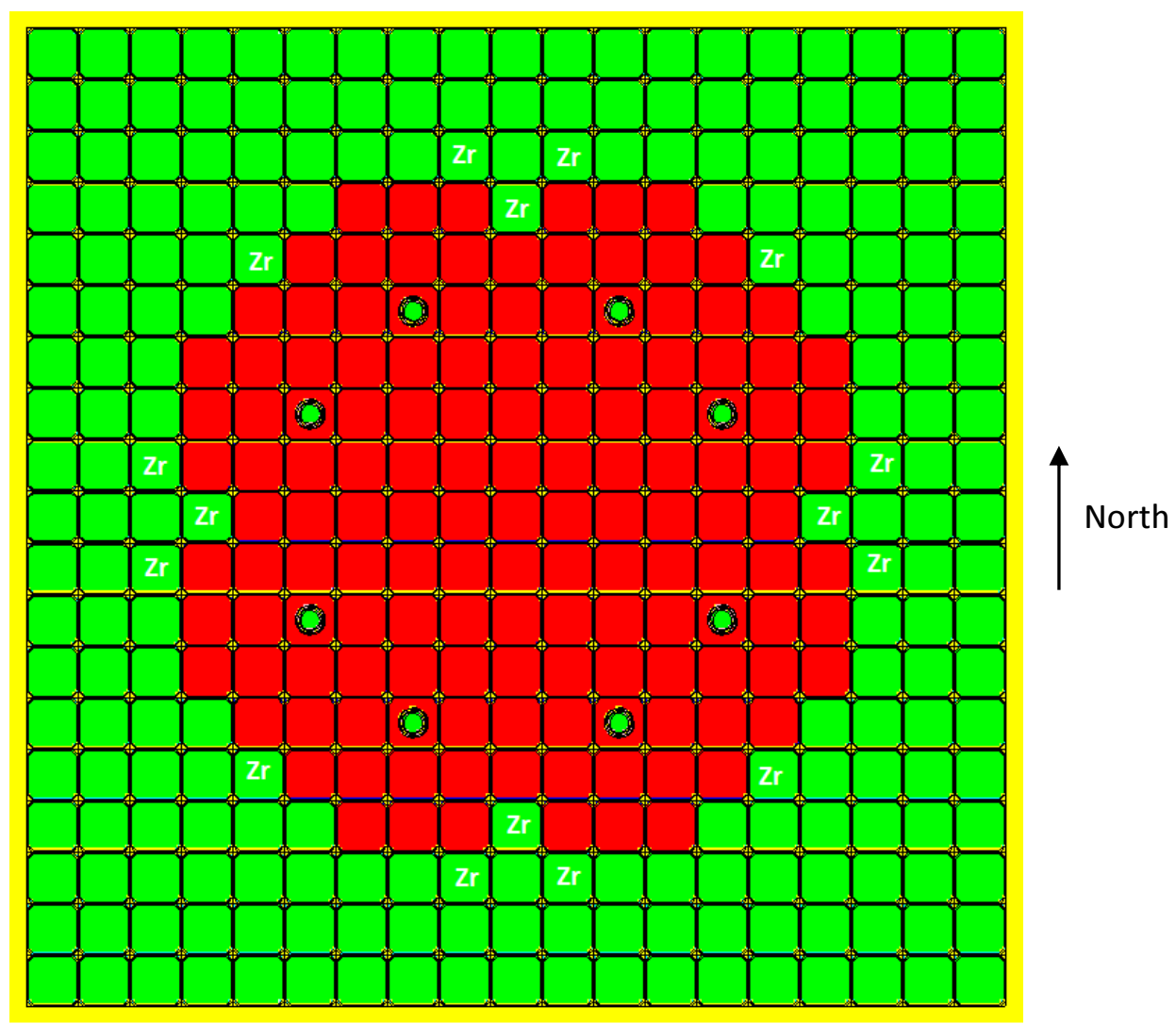

Figure [5.1]: TREAT Minimum Critical Core Loading Map with 133 Standard (Red Solid Blocks) and 8 Control Fuel (Red Blocks with Hole at the Center) Assemblies. The 220 Green Blocks Represent the Graphite Aluminum Clad Reflector Assemblies and the 16 Green Blocks Labelled with 'Zr' the Zirc-3 Clad Reflector Assemblies. The Control Rods were $100 \%$ Withdrawn

Table [5.1]: MCNP Criticality Calculations for the Minimum Core Configuration with 133 Standard and 8 Control Fuel Assemblies for the Reported Combination of Aluminum and Zirc-3 Cladded Graphite Reflector Blocks

\begin{tabular}{|cccccc|}
\hline \multicolumn{7}{c|}{ Minimum Core (133 standard, 8 control) } \\
\hline \# Graphite Reflectors & \multicolumn{1}{c|}{$100 \%$ Graphitization } & $59 \%$ Graphitization \\
\hline Al-Clad & Zirc-3-Clad & $\boldsymbol{k}_{\text {eff }}$ & Std dev & $\boldsymbol{k}_{\text {eff }}$ & Std dev \\
\hline $\mathbf{2 2 0}$ & 0 & 0.98262 & 0.00015 & 0.99746 & 0.00015 \\
\hline $\mathbf{2 0 8}$ & 12 & 0.98491 & 0.00014 & 0.99988 & 0.00015 \\
\hline $\mathbf{2 0 4}$ & 16 & 0.98588 & 0.00015 & 1.00058 & 0.00015 \\
\hline
\end{tabular}


Table [5.2]: MCNP Calculated Deviation from Criticality in pcm for the Minimum Core Configuration with 133 Standard and 8 Control Fuel Assemblies for the Reported Combination of Aluminum and Zirc-3 Cladded Graphite Reflector Blocks

\section{Minimum Core (133 standard, 8 control)}

\section{\# Graphite Reflectors Deviation from Criticality (pcm)}

\begin{tabular}{|cccc|}
\hline Al-Clad & Zirc-3-Clad & $\mathbf{1 0 0 \%}$ Graphitization & $\mathbf{5 9 \%}$ Graphitization \\
\hline $\mathbf{2 2 0}$ & 0 & -1769 & -255 \\
\hline $\mathbf{2 0 8}$ & 12 & -1532 & -12 \\
\hline $\mathbf{2 0 4}$ & 16 & -1432 & 58 \\
\hline
\end{tabular}

As discussed above, the number of zirconium-cladded graphite reflector-elements ranges from 12 to 16 assemblies. The absolute value of the calculated deviation from criticality is between 1532 and 14327 $\mathrm{pcm}\left(\mathrm{pcm}=10^{-5}\right)$ with $100 \%$ graphitization for 12 and 16 zirconium cladded graphite reflector element cases, respectively. Deviation from criticality was calculated as 12 and $58 \mathrm{pcm}$ with $59 \%$ graphitization for 12 and 16 zirconium cladded graphite reflector element cases, respectively.

\subsection{Approach to Criticality}

The initial approach to criticality experiment was performed in TREAT using an incremental loading scheme. The TREAT reactor went critical on February 23, 1959 with a loading of 146 fuel elements. Figure 5.2 shows the loading sequence for the last 73 elements, beginning with loading \#1. The loading proceeded outwardly from the center in increments of 10 to 16 elements until criticality was achieved. During the experiment, a Pu-Be neutron source was placed in the center of the core. As soon as criticality was achieved, the neutron source was replaced with a fuel element.

The loading sequence of the last 73 elements was calculated with MCNP, but without modeling the neutron source. In the center of the modeled configuration, a graphite reflector element was added. Table 5.3 shows the criticality results for each core loading. In the actual minimum critical core, which was the core used in later measurements, the central graphite element was replaced with a fuel element and several peripheral elements were removed, resulting in a total of 133 standard and 8 control fuel elements.

Table [5.3]: MCNP Calculated $\mathbf{k}_{\text {eff }}$ for the 73 Fuel Assemblies Loading for $100 \%$ and $59 \%$ Graphitization

\begin{tabular}{|c|c|c|c|c|c|c|c|}
\hline \multirow[b]{2}{*}{$\#$} & \multirow{2}{*}{$\begin{array}{c}\text { Fuel } \\
\text { Assemblies }\end{array}$} & \multicolumn{3}{|c|}{$100 \%$ Graphitization } & \multicolumn{3}{|c|}{ 59\% Graphitization } \\
\hline & & $k_{\text {eff }}$ & std & $\begin{array}{l}\text { Reactivity } \\
\text { (pcm) }\end{array}$ & $k_{\text {eff }}$ & std & $\begin{array}{l}\text { Reactivity } \\
(p c m)\end{array}$ \\
\hline 1 & 73 & 0.81140 & 0.00013 & -23244 & 0.82668 & 0.00015 & -20966 \\
\hline 2 & 82 & 0.84283 & 0.00015 & -18648 & 0.85806 & 0.00014 & -16542 \\
\hline 3 & 92 & 0.87429 & 0.00015 & -14379 & 0.88926 & 0.00015 & -12453 \\
\hline 4 & 108 & 0.91445 & 0.00015 & -9355 & 0.92959 & 0.00015 & -7574 \\
\hline 5 & 124 & 0.94964 & 0.00015 & -5303 & 0.96444 & 0.00015 & -3687 \\
\hline 6 & 140 & 0.97921 & 0.00014 & -2123 & 0.99419 & 0.00015 & -584 \\
\hline Final & 146 & 0.98899 & 0.00014 & -1113 & 1.0039 & 0.00016 & 388 \\
\hline
\end{tabular}




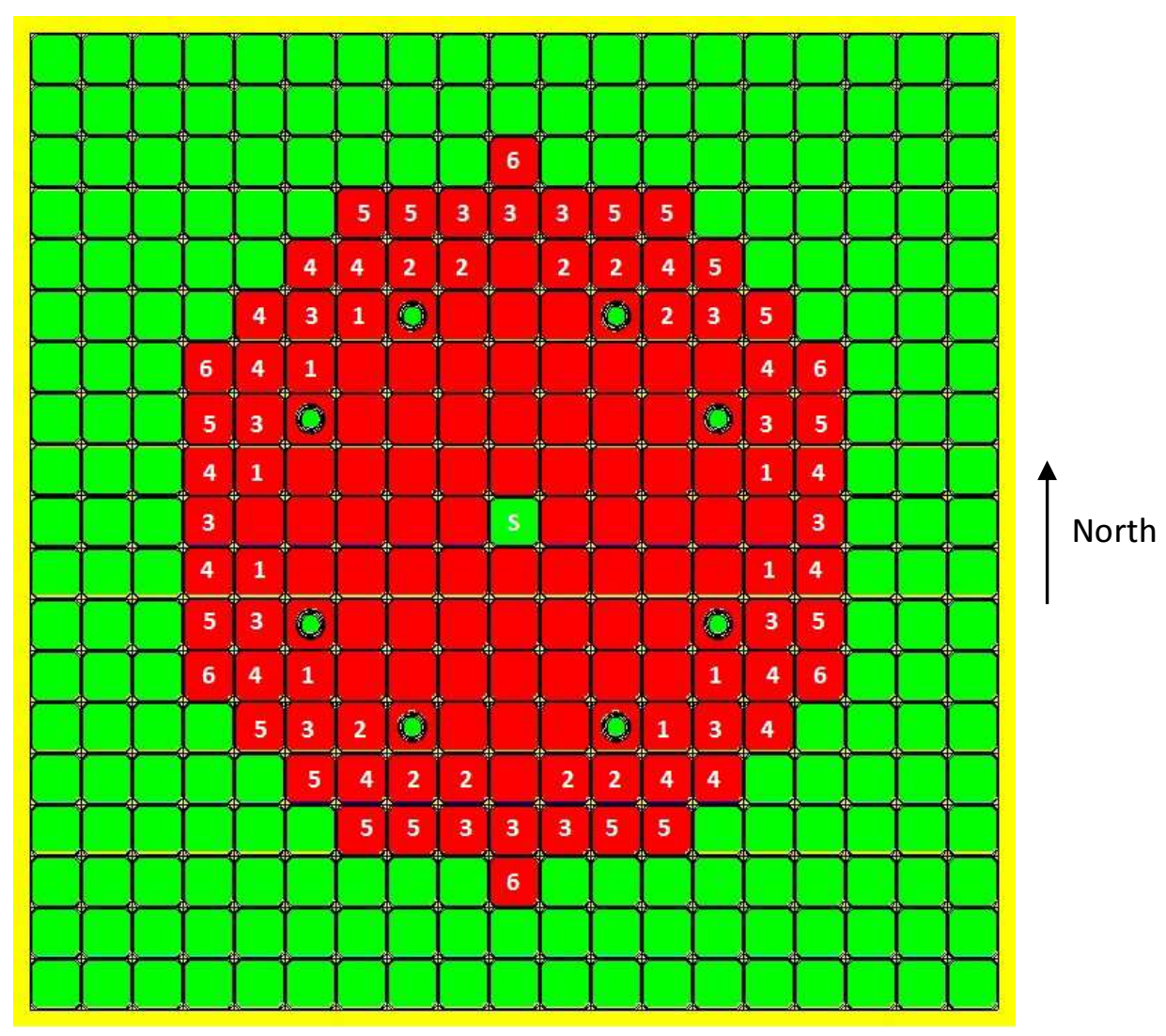

Figure [5.2]: Loading Sequence of the Last 73 Fuel Elements Beginning with Loading \#1. The Final Loading Consisted of 138 Standard (Red Blocks) and 8 Control Assemblies (Red Blocks with Hole in the Center). The 215 Green Blocks Represent the Aluminum Clad Graphite Reflector Blocks

\subsection{Temperature Coefficient}

The change in reactivity with respect to temperature is primarily due to the changes in the reactor kinetics associated with the increase in the average neutron importance. In the MCNP calculations, this was taken into account by adjusting the cross-section temperatures assumed in the model. The changes in the reactor size due to thermal expansion were neglected in this study. To evaluate the isothermal temperature coefficient of reactivity, the criticality of the TREAT core was determined after the reactor had been cooled overnight by circulating cold outside air through the reactor and building, and again after the reactor was heated by circulating warm inside air through the reactor. Thermocouples distributed throughout the core and reflector elements indicated essentially uniform temperature distributions of $295.15^{\circ} \mathrm{C}$ and $310.65^{\circ} \mathrm{C}$ for the cold and hot cores, respectively. The reactivity difference between the two states was evaluated to determine an isothermal temperature coefficient of reactivity. To simulate this experiment, the cross section libraries for $\mathrm{U}-235, \mathrm{U}-238$, and carbon, and for the $S(\alpha, \beta)$ treatment were produced for 400, 500 and 600 kelvin using the makxsf MCNP utility code [6]. Two separate cross section datasets were prepared for two levels of carbon graphitization, $100 \%$ and $59 \%$, to study effect of graphitization on the temperature reactivity coefficient calculation. All the rods were fully withdrawn. 
For the tally normalization the MCNP default value of $180 \mathrm{MeV}$ energy released per fission was assumed. Table 5.4 shows the MCNP calculated reactivity change as a function of uniform core temperature for the TREAT core with 133 standard and 8 control fuel assemblies.

Table [5.4]: MCNP Calculated Reactivity Change as a Function of Uniform Temperature Distribution for TREAT (149std/8cntl)

\begin{tabular}{|cccc|} 
Uniform Core Temp $(K)$ & \multicolumn{2}{c}{ Reactivity Decrease $(\Delta \mathrm{p})$} & \multirow{2}{*}{ 59\%/100\% ratio } \\
\cline { 2 - 3 } & 100\% Graphitization & $59 \%$ Graphitization & n/a \\
\hline $\mathbf{2 9 3 . 6}$ & $0.000 \%$ & $0.000 \%$ & 1.31 \\
\hline $\mathbf{4 0 0}$ & $1.738 \%$ & $2.271 \%$ & 1.25 \\
\hline $\mathbf{5 0 0}$ & $3.495 \%$ & $4.354 \%$ & 1.20 \\
\hline $\mathbf{6 0 0}$ & $5.229 \%$ & $6.250 \%$ & \\
\hline
\end{tabular}

In the case of the $100 \%$ graphitization, the reactivity changes linearly with core temperature, with a coefficient of determination (R-squared) of 1.000 . For the $59 \%$ graphitization, linear interpolation gives an R-squared of 0.998 . Figure 5.3 shows the calculated loss of reactivity as a function of uniform core temperature for the two levels of graphitization.

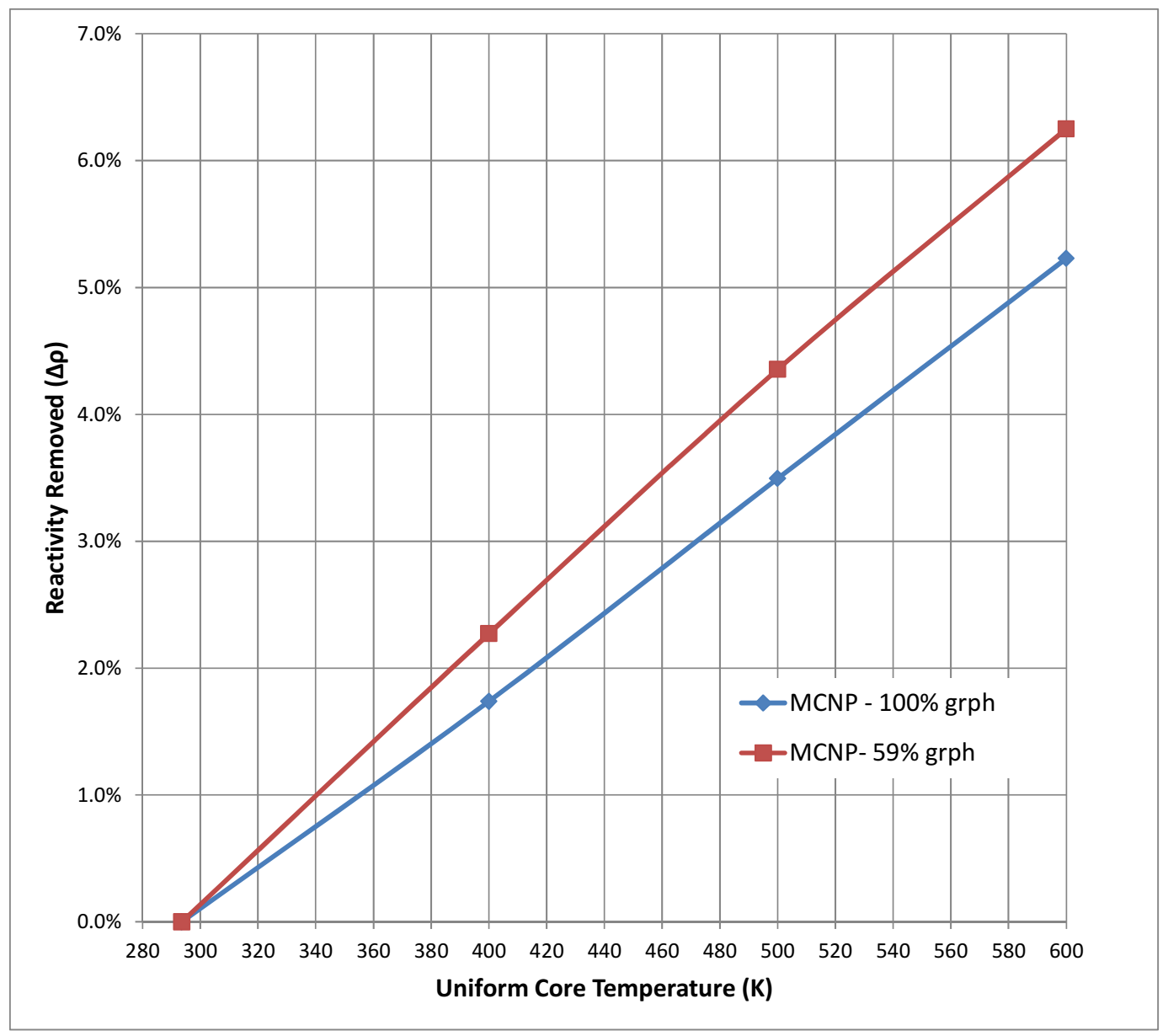

Figure [5.3]: MCNP Calculated Reactivity Loss as a Function of Uniform Core Temperature for $100 \%$ and $59 \%$ Graphitization

Table 5.5 shows the reported (based on the measurements with the $295.15^{\circ} \mathrm{C}$ and $310.65^{\circ} \mathrm{C}$ uniform temperature distributions) and calculated temperature coefficient values. The calculated-to-measured 
ratios for $100 \%$ and $59 \%$ graphitization are $0.92 \pm 0.10$ and $1.12 \pm 0.13$, respectively. Due to the high uncertainty of the measured temperature reactivity coefficient $(\sim 11 \%)$, the uncertainty of the calculated-to-measured temperature coefficient ratio $(C / M)$ is also high.

Table [5.5]: Reported and MCNP Calculated Temperature Reactivity for Uniform Core Temperature Change and the Resulting Calculated to Measured Ratio (C/M)

\begin{tabular}{|c|c|c|c|c|}
\hline \multirow{2}{*}{ Source } & \multicolumn{2}{|c|}{ Core Uniform Temp (K) } & \multirow{2}{*}{ Temp Coefficient ( $d \rho / K)$} & \multirow{2}{*}{$\mathrm{C} / \mathrm{M}$} \\
\hline & Initial & Final & & \\
\hline Reported [Ref] & 295.15 & 310.15 & $(-1.8 \pm 0.2) \times 10^{-4}$ & - \\
\hline MCNP - 100\% & 293.6 & 600 & $(-1.67 \pm 0.01) \times 10^{-4}$ & $0.92 \pm 0.10$ \\
\hline MCNP - 59\% & 293.6 & 600 & $(-2.01 \pm 0.06) \times 10^{-4}$ & $1.12 \pm 0.13$ \\
\hline
\end{tabular}

\subsection{Neutron Flux Distribution}

The neutron flux distribution was measured throughout the core and reflector in the minimal core. The core was loaded with 135 standard and 8 control rod assemblies and was set at critical state with the North-East pair of rods withdrawn between 47.5 and 49.5 inches (see Figure 5.4). The neutron flux measurements were made using U-235 and Au-197 foils, with dimensions of $1 \mathrm{~cm} \times 1 \mathrm{~cm}$ square by $1 \mathrm{mil}$ thick. The foil locations are indicated on Figure 5.4 in white. All foil counting rates were normalized to the counting rate of the central foil, which was determined before and after each measurement. The uncertainties of the foil measurements and of the foil in-core positions are not known.

In the MCNP simulations, the North-East control rod pair was placed at $47.5 \mathrm{in}$. for all calculations. The MCNP F4 tally (track length estimate of cell flux) was used with the FM card (-6) to count the total number of fissions taking place inside the U-235 foils.

Figure 5.5 shows the measured and calculated U-235 axial fission rate for the two levels of carbon graphitization. There is very good agreement between the calculated and measured axial fission rate in the fuel region for both cases of graphitization. In the region below the fuel section $(z<-60 \mathrm{~cm})$, MCNP overestimates the U-235 fission rate by $8 \%$ and $6 \%$ for $100 \%$ and $59 \%$ graphitization, respectively. The values of this overestimation for the region above the fuel section $(z>60 \mathrm{~cm})$ are increased to $15 \%$ and $12 \%$ for $100 \%$ and $59 \%$ graphitization, respectively. 


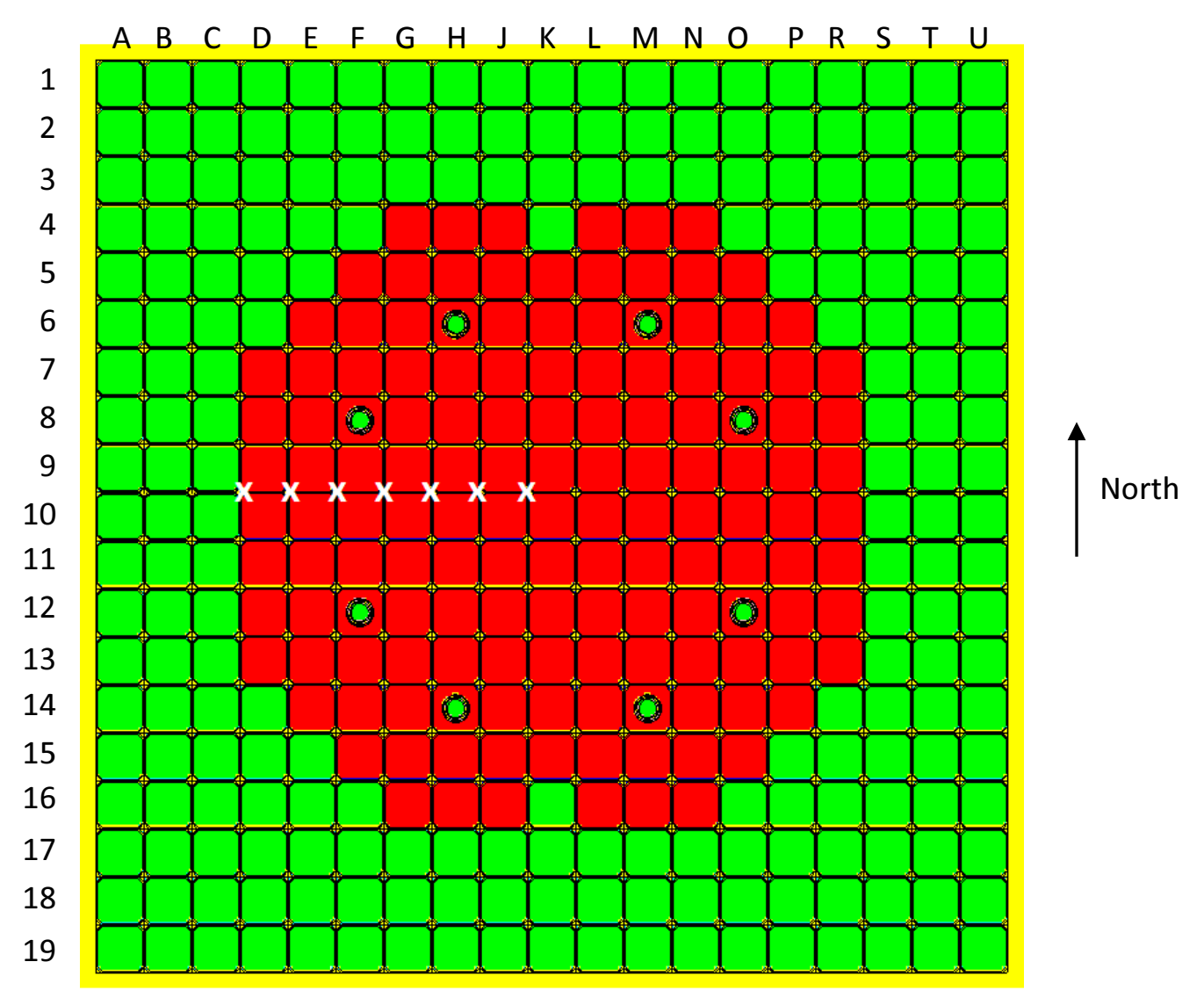

Figure [5.4]: TREAT Core Layout and the Position (Marked with White ' $x$ ') of the Foils Used to Measure the Neutron Flux Distribution

This difference may be attributed to the underestimation of the boron and other impurities in the axial graphite reflectors. Analysis has shown that the profile in the graphite region is indeed sensitive to the boron-10 content. However, since no significant effect is expected on the reactor performance due to this uncertainty, no further investigation was necessary.

Figure 5.6 shows the radial (west) measured at the axial mid-plane and calculated U-235 fission rate distributions for the two levels of graphitization. The calculations along the fuel section agree very well with the measurement. Again, overestimation is observed in the radial graphite reflector region that is formed by the graphite dummy elements surrounding the fuel region $(x>66 \mathrm{~cm})$, with errors of $14 \%$ and $11 \%$ for the $100 \%$ and $59 \%$ graphitization cases, respectively. 


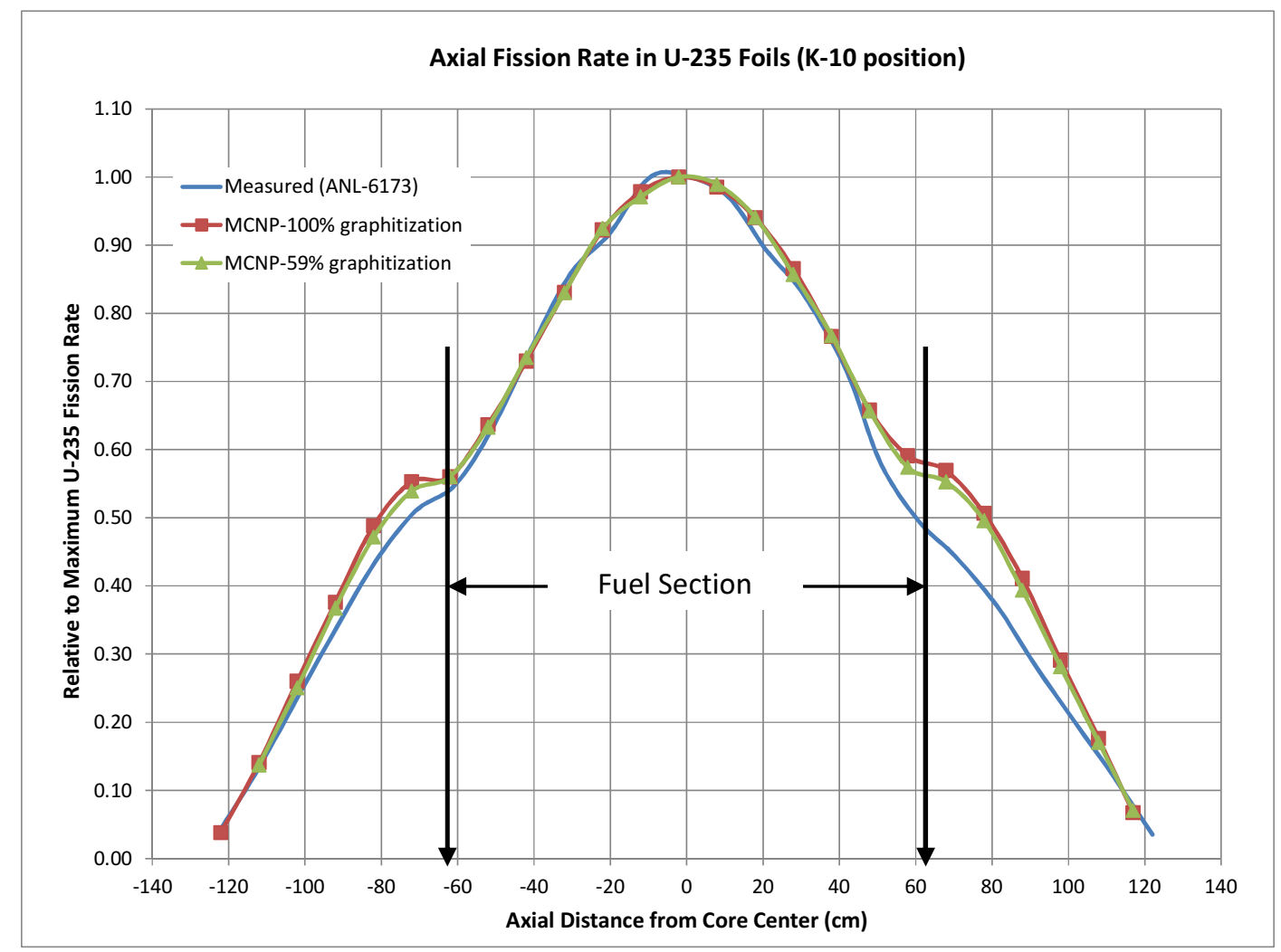

Figure [5.5]: Measured and Calculated (100\% and 59\% Graphitization) Axial Relative to Maximum U-235 Fission Rate for the K-10 Core Position

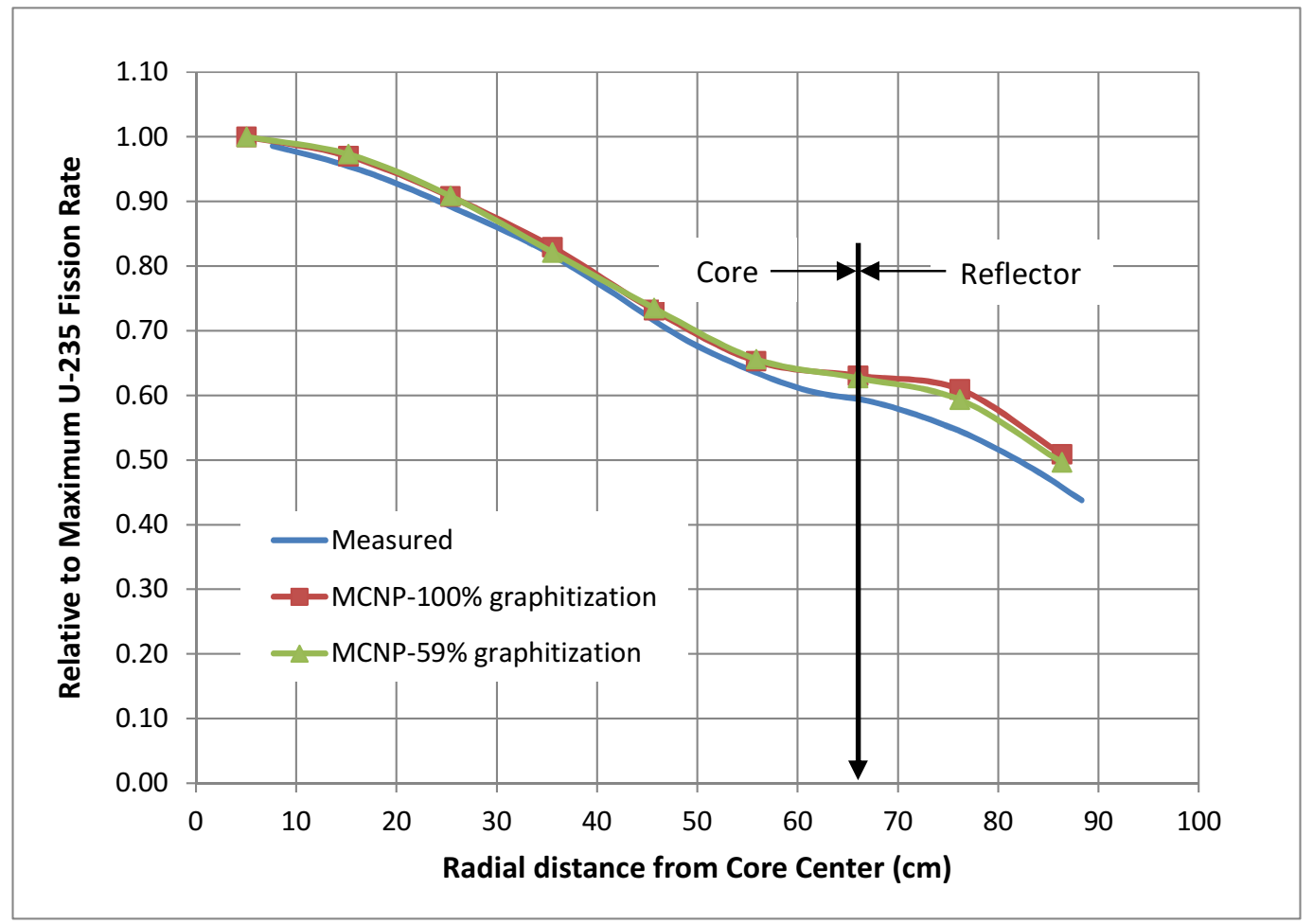

Figure [5.6]: Measured and MCNP Calculated (100\% and 59\% Graphitization) Radial (West) Relative to Maximum U-235 Fission Rate 
Additional axial foil measurements were also made using one-mil-thick gold foils ( $1 \mathrm{~cm} \times 1 \mathrm{~cm}$ square). The F4 tally (track length estimate of cell flux) with the FM (-2) multiplier (total absorption) was used to count the activation rate of the Au-197 foils. The measured values of relative-to-maximum activation rate, along with the MCNP calculated values for the two levels of graphitization, are shown in Figure 5.7.

As in the U-235 foils case, there is very good agreement between the results of the calculations and the measurements. The effect of the different graphitization in the Au-197 activation rate is negligible. It should be noted that the measurement results were not clearly marked to indicate where the top and the bottom of the fuel were, so it was assumed to be the same format with Figure 5.5 (where the top and bottom were indicated by the experimenters).

Above the reflector MCNP overestimates the measured activation rate by $12 \%$ and $11 \%$ for the $100 \%$ and $59 \%$ graphitization, and below the fuel section it underestimates the respective values by $8 \%$ for both levels of graphitization.

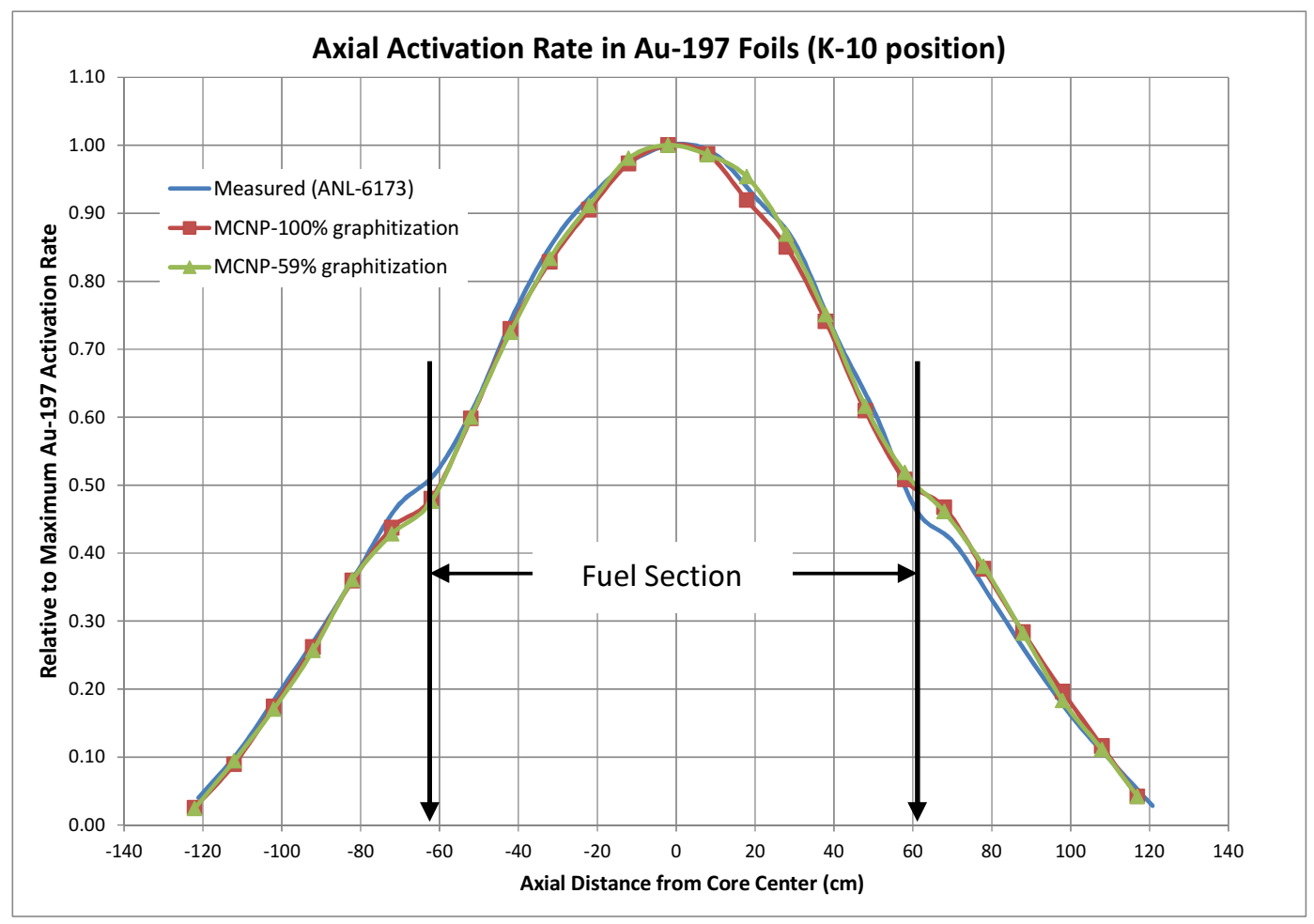

Figure [5.7]: Axial Distribution of the Relative to Maximum Au-197 Activation Rate for K-10 Core Position

\subsection{Temperature Distribution}

The temperature distribution in the core was measured by chromel-alumel thermocouples housed in special thermocouple fuel elements. The core configuration for this measurement had 149 standard and 8 control fuel assemblies. The core location of the special elements is shown in Figure 5.8. Table 5.6 describes the number and location of thermocouples inside each special element. Complete mapping of the core was not done, but representative temperatures both axially and radially were obtained after heating the core at a constant power of $100 \mathrm{~kW}$ without coolant flow. The axial temperature distribution 
was obtained from thermocouples located in the fuel region of the central fuel element (K-10). Control rod pair \#1 (North-East) was inserted to achieve criticality, and the rest of the rods were totally withdrawn. Neither the position of rod pair \#1 nor the time duration of the experiment was reported.

In the MCNP TREAT model, the fuel region of the fuel elements was divided in 15 axial segments, and the fission energy deposition was calculated for each segment using the F6 tally (track length estimate of energy deposition) in neutron/photon coupled mode. The tally was normalized using the $180 \mathrm{MeV}$ energy release per fission that is the default value in MCNP. Since the withdrawal of the control rod pair \#1 was unknown, the critical position was calculated with MCNP for the $59 \%$ graphitized core. The same configuration was used in the $100 \%$ graphitization case. Since there was no coolant flow during the experiment, the final temperature of each fuel assembly was calculated, approximating the fuel heating with an adiabatic process. The final temperature was calculated using the relative power density, the total core energy of $250 \mathrm{MJ}$, and the reported TREAT fuel heat capacity as a function of temperature [3] (Figure 5.9). The total core energy and the time duration of the experiment were not reported, so the total core energy used to calculate the temperature distribution from MCNP was determined as such to produce equal-to-the-measured hot-spot temperature (approximately $180^{\circ} \mathrm{C}$ ). The MCNP calculations were compared with the measurement in terms of relative-to-the maximum temperature.

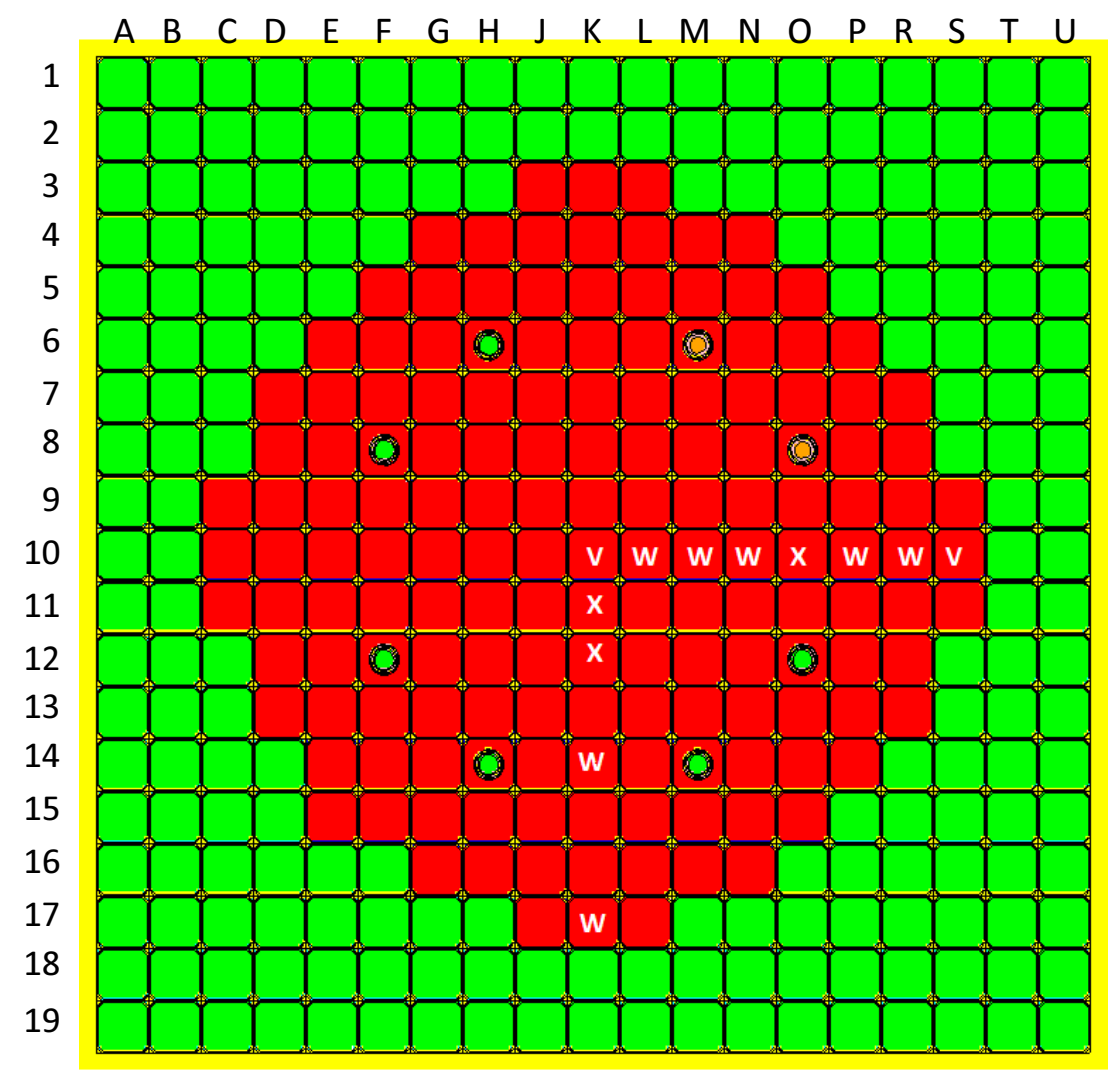

Figure [5.8]: TREAT Core Layout Used in Temperature Distribution Measurements. The Different Color of the Control Rods Located at the North-East Indicates that this Pair was Partially Inserted to Maintain Criticality. The Fuel Assemblies Marked Represent the Thermocouple Locations. Refer to Table 5.6 for the Exact Location of the Thermocouples. 
Table [5.6]: Thermocouple Location Inside the Special Fuel Elements Used to Measure the In-Core Temperature

\begin{tabular}{|c|l|}
\hline Element Label in Figure 5.8 & $\begin{array}{l}\text { Element Thermocouple Locations } \\
\text { Vour thermocouples spaced } 6,18,30 \text { and } 42 \text { in. from the top } \\
\text { of the } Z r \text { can in the fuel section }\end{array}$ \\
\hline $\mathbf{W}$ & $\begin{array}{l}\text { Four thermocouples spaced } 7 / 8 \text { in. above the } Z r \text { can in the } \\
\text { upper reflector, } 24 \text { in. from top of } Z r \text { can in the fuel section, } \\
\text { on the } Z r \text { skin-mid-point of } Z r \text { at corner and } 9 / 16 \text { in. below } \\
\text { the } Z r \text { can in the lower reflector }\end{array}$ \\
\hline $\mathbf{X}$ & $\begin{array}{l}\text { Two thermocouples spaced } 24 \text { in. from top of } Z r \text { can in the } \\
\text { fuel section and } 1 \text { in. above the } Z r \text { can (upper reflector) }\end{array}$ \\
\hline
\end{tabular}

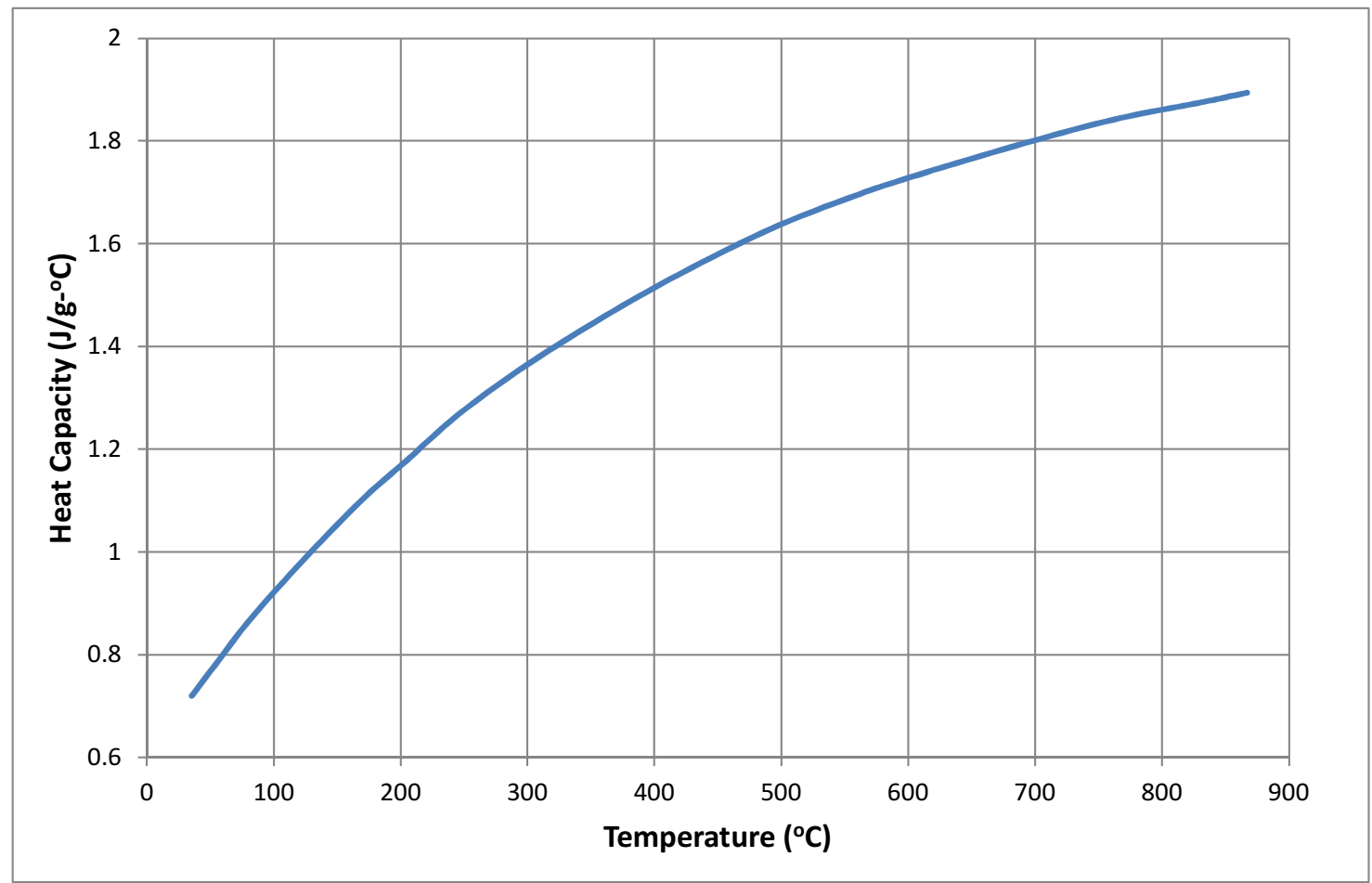

Figure [5.9]: TREAT Fuel Heat Capacity as a Function of Temperature

The calculated temperature distributions are expressed relative to the maximum value and are compared to the reported distributions. Figure 5.10 shows the axial temperature distribution in the central fuel assembly (K-10).

Figures 5.11 and 5.12 show the radial temperature distributions in the East and South directions, respectively. In all three figures, the curves for the two graphitization levels almost completely overlap. 


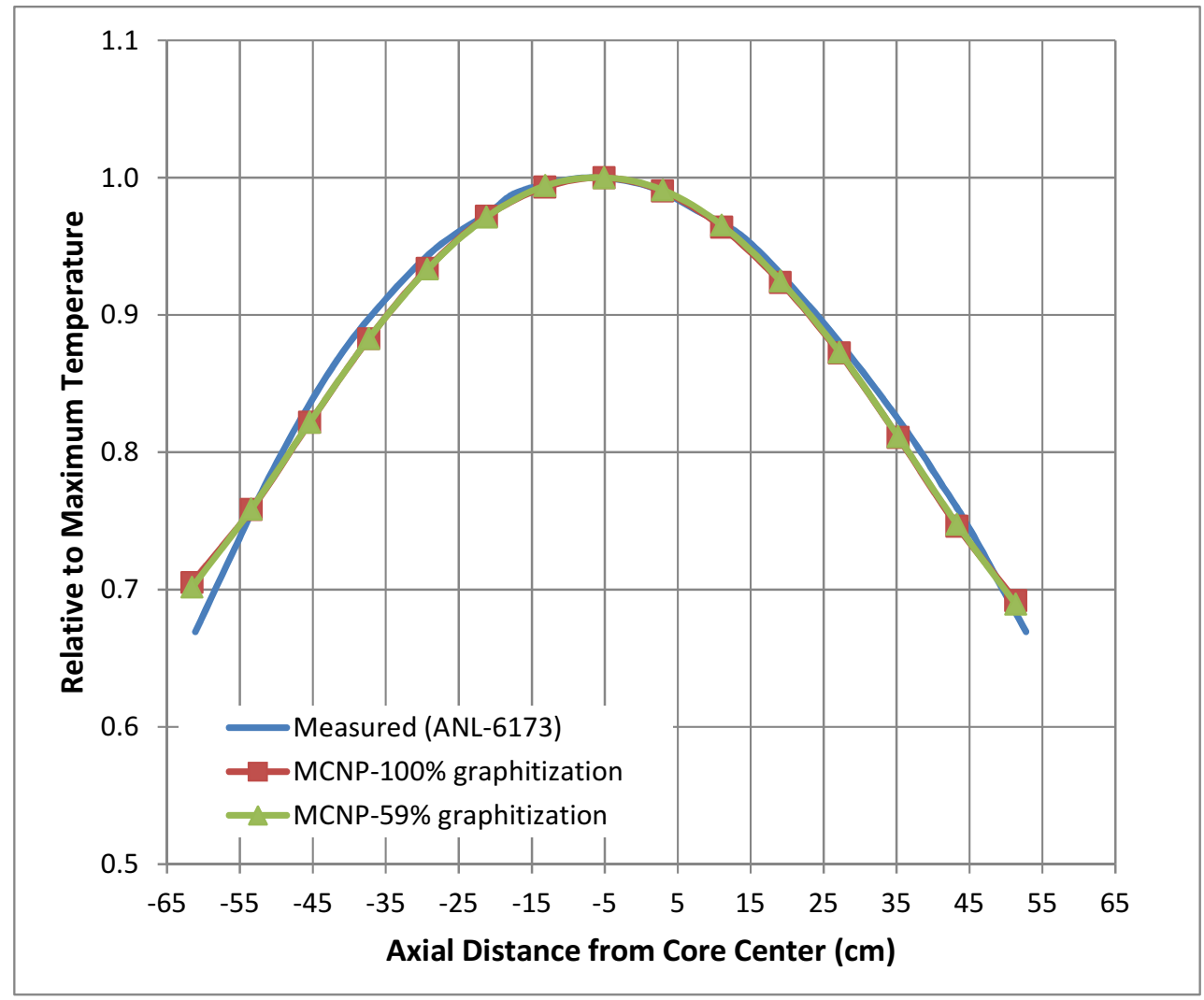

Figure [5.10]: Axial Relative-to-Maximum Temperature Distribution for Central Fuel Assembly (K-10). The Distance in the MCNP Results is from Core Center to the Center of the Fuel Assembly.

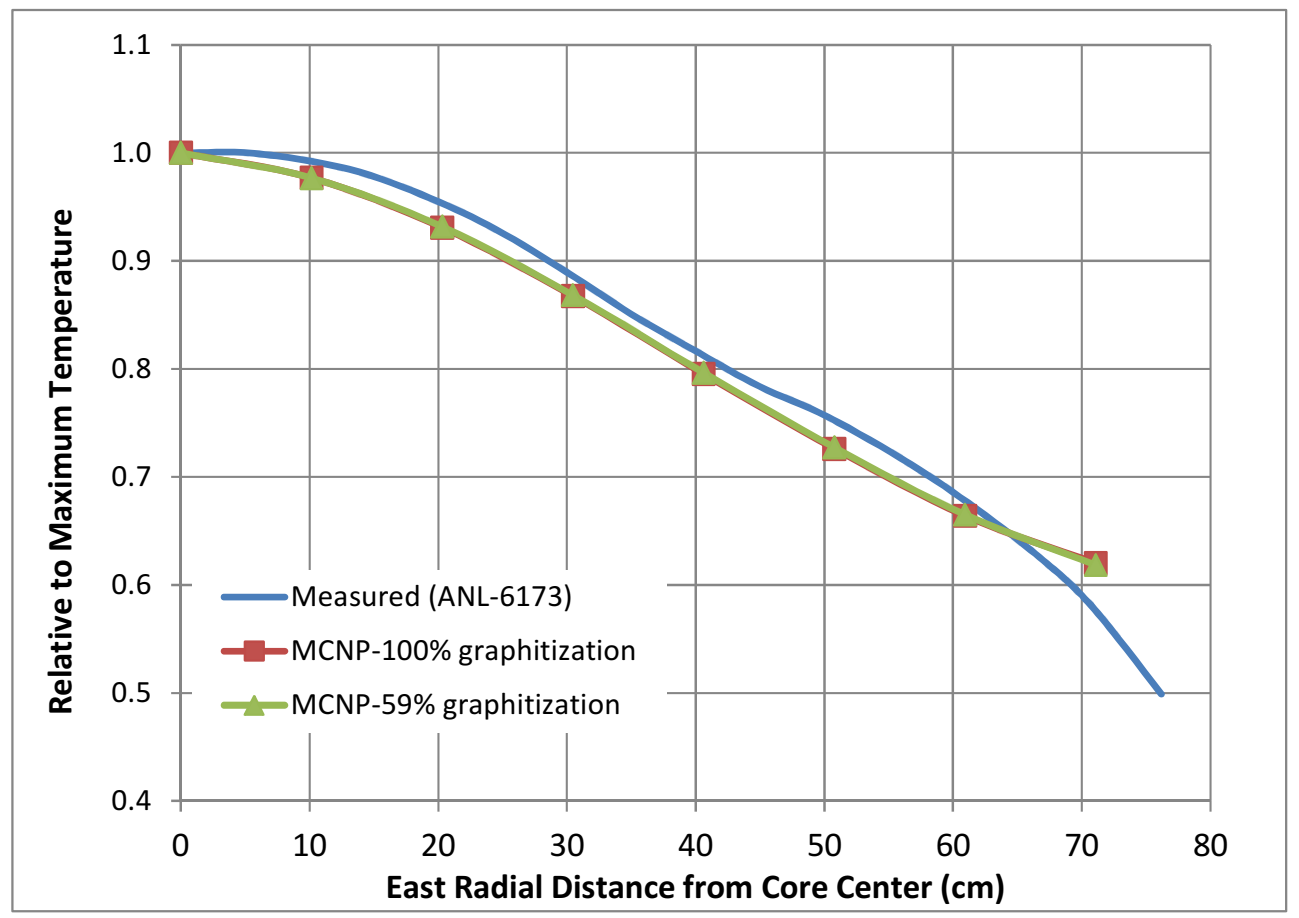

Figure [5.11]: Radial (East Direction) Relative-to-Maximum Temperature Distribution 


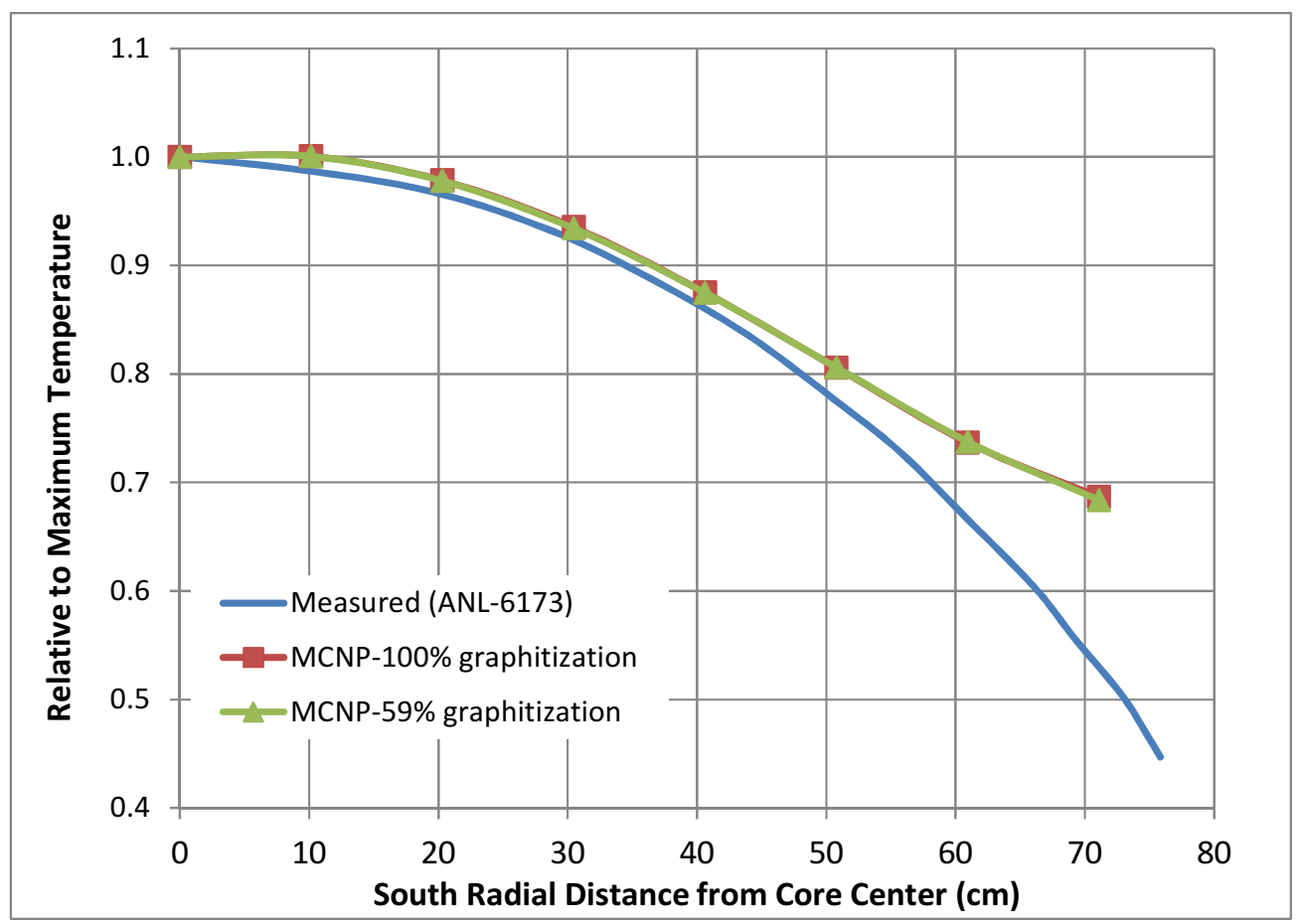

Figure [5.12]: Radial (South Direction) Relative to Maximum Temperature Distribution

The MCNP calculated temperature distributions are generally in good agreement with the measurements, but large differences are evident close to the edge of the fueled core. In the region with the largest error, the MCNP calculations overestimate the temperatures by $36 \%$. However, it should be noted that the measurement uncertainties are unknown, and the number of assemblies with thermocouples is limited to five (so there are very few measurement data points).

\section{Conclusions}

A set of steady-state experiments performed during the first six months of operation of the original TREAT core were simulated with MCNP to establish the ability of the model to estimate the core's critical loading, the neutron flux distribution and the temperature distribution. The core configurations used in those experiments were relatively simple (there were no test vehicles in the core, and there was very little control rod insertion) and were well-documented in the ANL-6173 report.

Based on the level of agreement between the measurements and the MCNP calculations, and considering the lack of knowledge of specific experimental parameters and of the uncertainties involved, the TREAT MCNP model is considered validated. 


\section{References}

[1] R W Swanson, L J Harrison, "The Effect of Carbon Crystal Structure on TREAT Reactor Physics Calculations", 1988 International Reactor Physics Conference, Jackson Hole, Wyoming 18-21 September 1988.

[2] R O Brittan, R Doerner, Unpublished Information, Argonne National Laboratory, November 1970.

[3] D G Naberejnev, Unpublished Information, Argonne National Laboratory, 2002 - 2003.

[4] Kirn F, J Boland, H Lawroski, R Cook, "Reactor Physics Measurements in TREAT", ANL-6173, October 1960.

[5] J R Liaw, Unpublished Information, Argonne National Laboratory, December 1979.

[6] Forrest B Brown, "The makxsf Code with Doppler Broadening", LA-UR-06-7002, 2006. 


\section{Appendix A: Changes in the MCNP Model (compared to ANL/GTRI/TM- $13 / 4)$}

Several changes have been made to the TREAT MCNP model since the simulations reported in ANL/GTRI/TM-13/4 were performed. Both the geometry and material compositions have been updated to reflect data found in recently acquired references. A full description of the parameters assumed in the current MCNP model will be provided in a separate report, and a brief summary of the key model updates is given below.

\section{A1. Composition Changes}

In the early simulations, many of the compositions in the MCNP TREAT model were based on secondary sources that cite the Brittan-Doerner memo [2], which was not then available. When this memo was obtained, it was found that for some compositions, several individual isotope percentages were incorrectly reported in the secondary sources. In addition, the memo shows an incorrect $\mathrm{B}^{10}$ enrichment in natural boron (18.9\% instead of $19.9 \%)$. The MCNP compositions were updated to reflect this new information.

\section{A2. Geometry Changes}

Using the information in the Brittan-Doerner memo, the dimensions of the fuel meat in the TREAT fuel elements were adjusted slightly. The current model assumes a fuel section square of 3.81 in. x 3.81 in., with a chamfered corner length of 0.6120 in.

Several new engineering drawings of the TREAT components were also obtained, which allowed for additional improvements to the model. The Zircaloy cladding of the graphite blocks was set to a thickness of 25 mils. In the permanent radial reflector, the diameter of the measurement holes was changed from 6 in. to $6.5 \mathrm{in.}$ In addition, 46 1-in.-diameter holes were added to the reflector to account for the reflector supporting bolt holes. These reflector changes removed a significant amount of graphite from the system, which caused a slightly reduced k-effective value.

In the fuel element upper graphite region, the model was adjusted to include the fuel outgas tube. This, too, removed some of the graphite from the system. The geometry of the outgas tube for a standard fuel element is shown in Figure [A.1. In the control rod elements, the outgas tube is positioned off-center, to allow for the rod (Figure [A.2) to be accommodated in the center. 


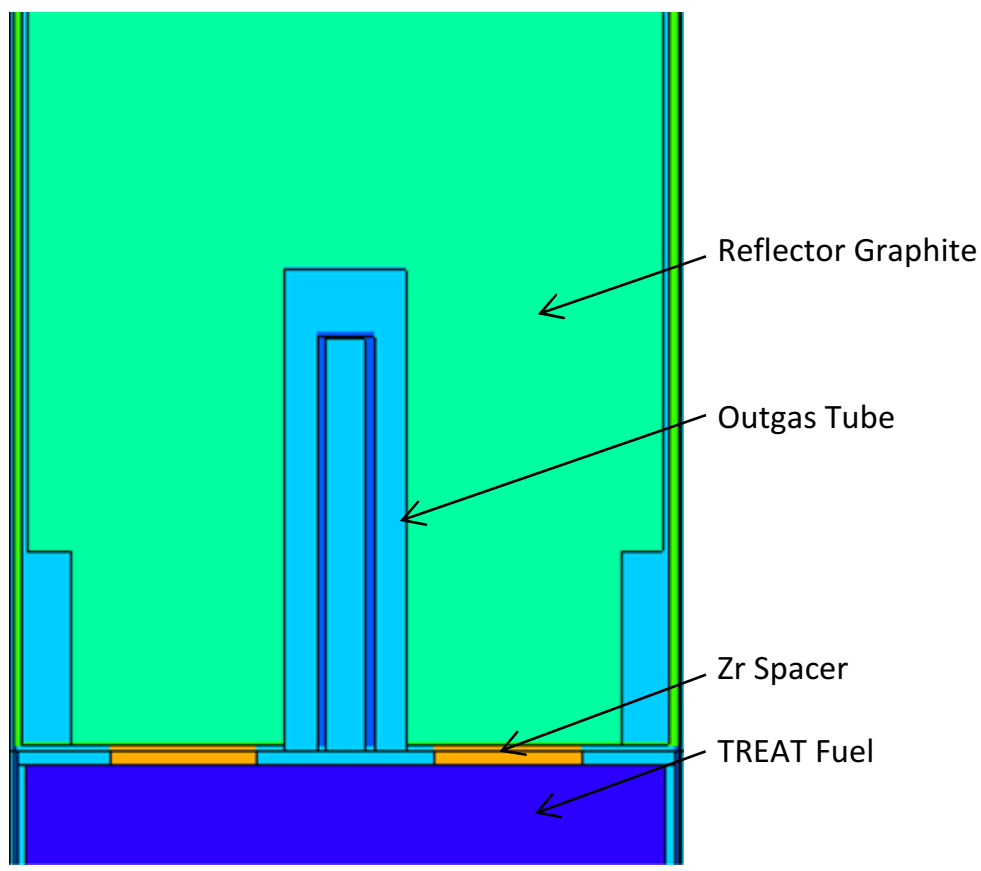

Figure [A.1]: Upper Graphite Reflector and Outgas Tube of a Standard TREAT Fuel Assembly

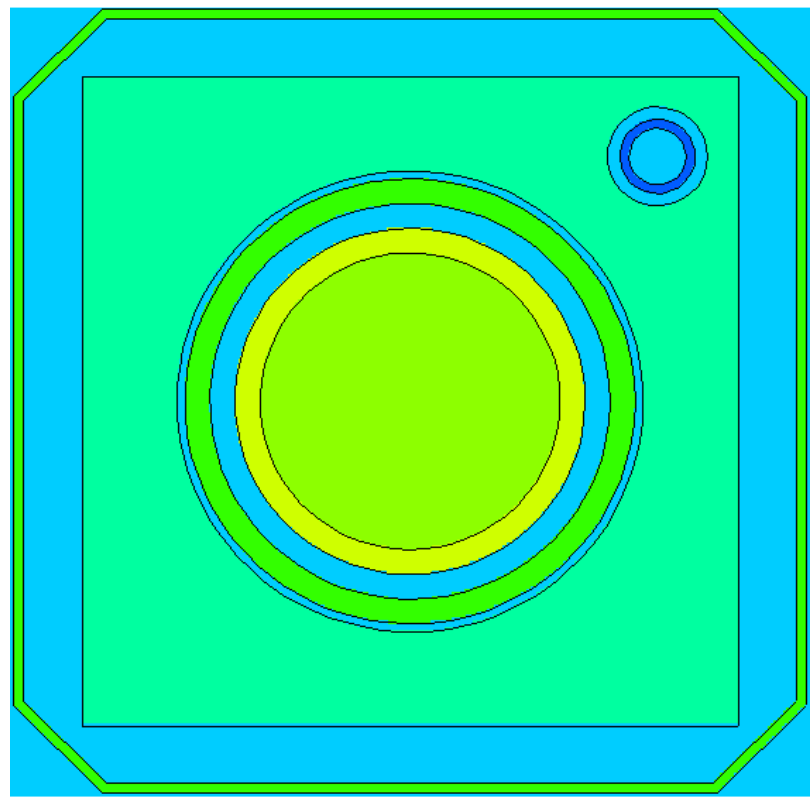

Figure [A.2]: Cross-section View of Graphite Reflector Region, Including Outgas Tube, for a Control Rod TREAT Fuel Assembly 
Argonne

Nuclear Engineering Division

Argonne National Laboratory

9700 South Cass Avenue, Bldg. 208

Argonne, IL 60439-4842

www.anl.gov 